\title{
Difference in Quality of Foster Children's Sleep in the Nursery (Day Care) and House in Mataram
}

\author{
Rias Pratiwi Safitri \\ STIKES YARSI Mataram \\ Mataram, Indonesia \\ rias_dangkem@yahoo.co.id \\ Baiq Nurul Hidayati \\ STIKES YARSI Mataram \\ Mataram, Indonesia
}

\author{
Fitri Romadonika \\ STIKES YARSI MATARAM \\ Mataram, Indonesia
}

\begin{abstract}
Sleep disorders in children are quite often experienced by parents, but unfortunately, these conditions are rarely treated seriously and considered normal. In the age of 6 months to 2 years about $30 \%$ of children suspected of having trouble sleeping and about $20 \%$ of children aged 2-5 years of experience. When this disorder untreated it can seriously be accompanied various behavioral disorders and learning disorders in school. This study aimed to analyze the differences in the quality of sleep of children in foster care in day care and at home. The design used in this research is descriptive research with the cross-sectional approach, which is to identify differences in the quality of sleep of children in child care (day care) Al-Hikmah Kekalik and children who are in foster mothers in the Gegutu area. The population used in the study are all the children in the care of alwisdom and her children in foster care in the area. A population of 28 people in al-wisdom and 28 people in Gegutu. The sampling technique used is total sampling. Based on the description of the results of these studies it is known that sleep quality dropped off children at daycare al-wisdom is better in comparison with children who are in foster care by his mother at home. This is shown by the standard deviation and the mean measurement of the quality of sleep of children in al-wisdom that 4,838 elementary and Mean 32.07, while children are cared for at home by her mother had the standard deviation, and the mean is $\mathbf{1 0}$ 134 and Mean 37.50 SD. The smaller the standard deviation and the mean of the measurements showed better sleep quality (quality of sleep al-wisdom Gegutu home sleep quality).
\end{abstract}

Keywords—Child; Sleep; Quality

\section{INTRODUCTION}

The child is a unique individual and has a need by their development stage, one of which is sleep. Sleep is one of the pleasures and great mercy value of the many pleasures given by God Almighty to man. Although human force do the hard work and tiring, Allah does not allow someone not to sleep and will give you a break by the way drowsy and then fell asleep. Decided to sleep thinking the man of relations activity and physical activity. Loss of consciousness in sleep is a pleasure, because when before sleeping there that feels pain, then the pain can disappear at bedtime.
In children, sleep is a basic requirement for optimal growth. The quality of sleep in children is influenced by several factors among which there is fatigue, stress, sleep process, time, sleep quality, sleep routine, medication, and lifestyle. The quality of proper sleep is as important as good nutrition and adequate exercise. Someone require the amount of sleep and rest are different. Not exactly the amount of sleep a person the ability to concentrate, make decisions, and activities in daily activities will decrease. Achieving a good quality sleep is important for health, as well as recovering from an illness. In order for our bodies to stay healthy and fit throughout the day then one way is to maintain the quality of sleep quality. Often a person feels weak and lethargic because they are too excessive in the use of energy in their daily activities, for the sleep and rest can recover the energy lost energy, fatigue and difficult to control their emotions .[1]

When someone less rest, they will be irritable, tertek Sleep disorders in children is quite common. The prevalence rate ranges from $25 \%$ to $40 \%$, and it is a number that is persistent. In Indonesia, the prevalence of sleep disorders in children aged under three years amounted to $44.2 \%$. Another study says that $30 \%$ of children under four years of experience in the form of sleep disorder often wake up at night. In Beijing, China the prevalence of sleep disorders in children aged 2-6 years at $23.5 \% .8$ To date, no studies in Indonesia are examining the relationship between sleep disturbances in children with growth.[2]

The prevalence of growth retardation has sufficient big numbers. Prevalence short stature reached $42 \%$. While children who fail to grow has a prevalence of $40 \%$ in children under five years, a total of about 125 million, with an increase in prevalence with increasing age. Retardation of growth is the main problem faced by the developing countries have a prevalence of $50 \%$ among children aged under five years. Growth in children is affected by various factors, including factors preconception, prenatal, natal, and postnatal. Postnatal factors one of which is a hormonal disorder factor. Hormonal disorders can be caused by sleep disorders that can disrupt the synthesis and function of growth hormone. 
Sleep disorders in children is quite often experienced by parents but unfortunately, these conditions are rarely treated seriously and considered normal. 20-40 children under three months of ganggan sleep. In the age of 6 months to 2 years about $30 \%$ of children suspected of having trouble sleeping and about $20 \%$ of children aged 2-5 years of experience. When this disorder untreated it can seriously be accompanied various behavioral disorders and learning disorders in school.

The amount of the percentage of sleep disturbances that occur in children requires further analysis associated with the root causes of sleep disorders in children. It is highly influenced by invoice parenting, nutritional status, quality of sleep and eating are adopted by parents as well as the environmental conditions. In the current era of care is given to caregivers or dropped off because of busy parents so that differences in parenting that can affect the child's sleep quality, especially in urban areas.[3]

The flurry of both parents working will lead to reduced attention to the child, then the child's natural that left at the daycare in the hope they get better care. Most of the parents who entrust their children do not know what are the factors that must be considered and taken into account in selecting a suitable daycare for their child's development.[4]

The quality of care provided of course very important role in the development of children, such as a caregiver should be able to provide the need of feeling loved, feeling of warmth and attention in parenting. But these things can be felt after going through the process in a certain period where a toddler has been deposited at the site. Another factor that can be viewed directly as an input for selecting the appropriate child care is to look at the physical condition of the element architects, comfort and safety factor, the factor of the facility and learning programs provided to children in helping to stimulate the body's development. Whereas in times of under five children can learn a very high with after they exceed the age of five.[2]

Also, there are also parents who still entrust their babies to caregivers at home. But they put their babies to preschool or places that provide education in early childhood. With hope, their children still get an education or stimulation by its growth and development. Results of research conducted in Malang on July 24, 2004, [1] mothers who leave their children in the landfill 50\% say their smart dialing, 30\% said their development was natural, and $20 \%$ said do not know the development of children. Based on the research results as well, about $50 \%$ of the capabilities of the intelligence of adults have occurred when children aged 4 years, $8 \%$ had occurred rapid development of brain tissue when the child is 8 years old and peaked when the child was 18 years, and after that even if repairs nutrition will not affect cognitive development[5].

Based on this background that the issue of quality of sleep can affect child development that needs to be done regarding the quality of sleep detection the better the child in foster care in child care (TPA) and at home. The above description attracted the attention of researchers to determine differences in the quality of sleep of children in foster care in child care and at home[6].

\section{RESEARCH METHODS}

The design used in this research is descriptive research with the cross-sectional approach, which is to identify differences in the quality of sleep of children in child care (day care) AlHikmah Kekalik and children who are in foster mothers in the Gegutu area. The population used in the study are all the children in the care of al-wisdom and her children in foster care in the area. A population of 28 people in al-wisdom and 28 people in Gegutu. The sampling technique used is total sampling.

\section{RESULT}

a. Long sleep

\begin{tabular}{|l|l|c|c|c|c|}
\hline \multirow{2}{*}{ Place } & \multicolumn{4}{|c|}{ Caracteristic } \\
\cline { 2 - 4 } & \multicolumn{1}{|c|}{ Long Sleep } & $\sum$ & $\%$ & $\begin{array}{c}\text { Mea } \\
\boldsymbol{n}\end{array}$ & $\boldsymbol{S} \boldsymbol{D}$ \\
\hline Himah & Good & 0 & 0 & 6.39 & $\begin{array}{c}0.56 \\
7\end{array}$ \\
\cline { 2 - 4 } & Enough & 28 & 100 & & \\
\cline { 2 - 4 } & Less & 28 & 100 & & \\
\hline \multirow{2}{*}{ Total } & & 7 & 25 & 4.25 & 1.43 \\
\hline Gegutu & Good & 21 & 75 & & \\
\cline { 2 - 4 } & Enough & 0 & 0 & & \\
\cline { 2 - 4 } & Less & 28 & 100 & & \\
\hline \multirow{2}{*}{ Total } & & 28 & & \\
\hline
\end{tabular}

Based on the description of the difference in sleep duration are known differences in sleep duration of children in Leave at daycare $28(100 \%)$ included in the category enough, while children are in foster care by his mother in Gegutu 7 $(25 \%)$ in the category of good and 21 people $(75 \%)$ in the category enough. Old bed of the percentage of children cared for in his old home longer (SD 0567) than children in day care are entrusted al-wisdom (SD 1.430).

b. Sleeping Habits

\begin{tabular}{|l|l|c|c|c|c|}
\hline \multirow{3}{*}{ Place } & \multicolumn{5}{|c|}{ Caracteristic } \\
\cline { 2 - 5 } & $\begin{array}{c}\text { Sleeping } \\
\text { Habits }\end{array}$ & $\sum$ & $\%$ & $\begin{array}{c}\text { Mea } \\
\boldsymbol{n}\end{array}$ & SD \\
\hline $\begin{array}{l}\text { Al } \\
\text { Himah }\end{array}$ & Good & 8 & 29 & $\begin{array}{c}25.6 \\
8 .\end{array}$ & $\begin{array}{c}4.62 \\
7\end{array}$ \\
\cline { 2 - 4 } & Enough & 20 & 71 & & \\
\cline { 2 - 4 } & Less & 0 & 0 & & \\
\hline \multirow{2}{*}{ Total } & & 28 & 100 & & \\
\hline \multirow{2}{*}{ Gegutu } & Good & 5 & 18 & 33.2 & 9.94 \\
\cline { 2 - 4 } & Enough & 21 & 75 & & \\
\cline { 2 - 4 } & Less & 2 & 7 & & \\
\hline \multirow{2}{*}{ Total } & & 28 & 100 & & \\
\hline
\end{tabular}

Based on the description of the differences in sleep habits are known habit of sleeping children in daycare dropped off eight people $(29 \%)$ in both categories, 20 people $(71 \%)$ included in the category enough. While the children are in 
foster care by his mother in Gegutu have a habit of sleeping five people $(18 \%)$ in both categories, 21 people $(75 \%)$ in the category of pretty and $2(7 \%)$ in the category of less. Percentage of sleep habits of children care for day care alwisdom (SD 4627) is better than the children who are cared for at home Gegutu (SD 9594).

c. Sleep Quality

\begin{tabular}{|c|c|c|c|c|c|}
\hline \multirow[b]{2}{*}{ Place } & \multicolumn{5}{|c|}{ Caracteristic } \\
\hline & Sleep Quality & $\Sigma$ & $\%$ & $\begin{array}{c}M e a \\
n\end{array}$ & $S D$ \\
\hline \multirow{3}{*}{$\begin{array}{l}\text { Al } \\
\text { Himah }\end{array}$} & Good & 2 & 7 & \multirow{4}{*}{$\begin{array}{c}32.0 \\
7\end{array}$} & \multirow{4}{*}{$\begin{array}{c}4.83 \\
8\end{array}$} \\
\hline & Enough & 26 & 93 & & \\
\hline & Less & 0 & 0 & & \\
\hline Total & & 28 & 100 & & \\
\hline \multirow[t]{3}{*}{ Gegutu } & Good & 5 & 18 & \multirow[t]{4}{*}{$\begin{array}{c}37.5 \\
0\end{array}$} & \multirow[t]{4}{*}{$\begin{array}{c}10.1 \\
34\end{array}$} \\
\hline & Enough & 21 & 75 & & \\
\hline & Less & 2 & 7 & & \\
\hline Total & & 28 & 100 & & \\
\hline
\end{tabular}

Based on the description of the difference in sleep quality is known to the sleep quality dropped off children at daycare 2 (7\%) in the category of good, 26 (93\%) included in the category enough. While the children are in foster care by his mother in Gegutu have quality sleep five people (18\%) in both categories, 21 people $(75 \%)$ in the category of pretty and 2 $(7 \%)$ in the category of less. The sleep quality of the percentage of children who are cared for day care al-wisdom (SD 4838) is better than the children who are cared for at home Gegutu (SD 10 134).

Based on the description of the results of these studies it is known that sleep quality dropped off children at daycare alwisdom is better in comparison with children who are in foster care by his mother at home. This is shown by the standard deviation and the mean measurement of the quality of sleep of children in al-wisdom that 4,838 elementary and Mean 32.07, while children are cared for at home by her mother had the standard deviation and the mean is 10134 and Mean 37.50 SD. The smaller the standard deviation and the mean of the measurements showed better sleep quality (quality of sleep alwisdom (Gegutu home sleep quality).

The sleep quality was described from a long sleep and sleep habits of children, by a description of differences known sleep habits sleep habits of children in daycare dropped off eight people $(29 \%)$ in both categories, 20 people $(71 \%)$ included in the category enough. While the children are in foster care by his mother in gegutu have a habit of sleeping five people (18\%) in both categories, 21 people $(75 \%)$ in the category of pretty and $2(7 \%)$ in the category of less. Percentage of sleep habits of children care for day care al-wisdom (SD 4627) is better than the children who are cared for at home Gegutu (SD 9594).

Based on observation it is influenced by the conditioning time and sleep patterns by caregivers such as hours of sleep, comfortable sleeping space by using air conditioning, age groupings of children in one room so they are stimulated in accordance with his age and also the provision of massage baby after the bath is done routinely so that children become more relaxed and not nervous and could sleep soundly. While the children are in foster care by his mother in gegutu be less good sleep habits for mothers lack knowledge related sleep disorder symptoms in children so that some mothers let their children when experiencing difficulty falling asleep. Also they do not provide activities that can stimulate the child and the activity is not directed, so that disrupt sleep patterns

Meanwhile, based on the description of differences in sleep duration are known differences in sleep duration of children in Leave at daycare $28(100 \%)$ included in the category enough, while children are in foster care by his mother in gegutu 7 $(25 \%)$ in the category of good and 21 people $(75 \%)$ in the category enough. Old bed of the percentage of children cared for in his old home longer (SD 0567) than children in day care are entrusted al-wisdom (SD 1.430). From the observation of a long note on gegutu child sleep longer than in al-wisdom because their activities at al-wisdom and the number of children there are many so noisy that it interferes with children take rest.

\section{CONCLUSION}

Based on the description of the results of these studies it is known that sleep quality dropped off children at daycare alwisdom is better in comparison with children who are in foster care by his mother at home. This is shown by the standard deviation, and the mean measurement of the quality of sleep of children in al-wisdom that 4,838 elementary and Mean 32.07, while children are cared for at home by her mother had the standard deviation and the mean is 10134 and Mean 37.50 SD. The smaller the standard deviation and the mean of the measurements showed better sleep quality (quality of sleep alwisdom (Gegutu home sleep quality)

\section{REFERENCES}

[1] B. B. Bijari, S. Iranmanesh, F. Eshghi, and M. R. Baneshi, "Gentle Human Touch and Yakson: The Effect on Preterm 's Behavioral Reactions," vol. 2012, pp. 6-11, 2012.

[2] S. Beider and C. A. Moyer, "Randomized Controlled Trials of Pediatric Massage: A Review," vol. 4, no. November 2006, pp. 23-34, 2007.

[3] A. Manuscript, "NIH Public Access," vol. 109, no. 1, pp. 41-46, 2012.

[4] A. Mohammed and H. Sayed, "Impact of Tactile Stimulation on Neurobehavioral Development of Premature Infants in Assiut City," vol. 6, no. 8, pp. 93-102, 2015.

[5] F. Eshghi, S. Iranmanesh, B. B. Bijari, and F. Borhani, "Effects of Yakson Therapeutic Touch on the Behavioral Response of," vol. 17, no. 1, pp. 15-21, 2015.

[6] J. Peters, "Safe sleep and rest in child care," pp. 1-2. 